\title{
Blended Learning in English Language Teaching: Open Educational Resources Used for Academic Purposes in Tomsk Polytechnic University
}

\author{
Olga I. Shaykina
}

National Research Tomsk Polytechnic University, Russian Federation Email: nikol_2507@mail.ru

\author{
Doi:10.5901/mjss.2015.v6n3s5p255
}

\begin{abstract}
The study describes blended learning as an innovative teaching method which combines different learning approaches supported by flexible interactive platforms and resources that offer new environments to improve skills and upgrade competences. The concept of blended learning suggests that under current conditions the educational system up-to-date methods of traditional education can be optimally combined with the advantages of remote technologies. The components of blended learning are defined. The benefits of teaching foreign languages with blended learning method are identified. The essential factors to find a "right" blend are singled out. One of the most effective resources widely used in Tomsk Polytechnic University is a Virtual Learning Environment Moodle. The e-course "The world of work" developed in Moodle environment is represented. The survey of certain available open educational resources to support education that may be freely accessed, downloaded, reused, modified and shared by anyone is given. The conclusion about comprising free Internet repositories and online courses to make English language teaching process more effective is described.
\end{abstract}

Keywords: regional university, blended learning, information technology, open educational resources, Moodle.

\section{Introduction}

Teaching of foreign languages in general and English in particular, has undergone many changes in teaching methods, especially in recent decades, causing the development of a variety of innovative approaches and methods. Language teaching is a dynamic, constantly changing process in which the lack of fixed standards can be observed in comparison with other subjects.

Modern information technology has penetrated into all areas of people's lives, and teachers must take this into account and use their opportunities in their work. Without a doubt the role of a teacher is now changing and boundaries between him and the student are getting clear that facilitates cooperation. The role of the student who participates not only in gaining knowledge, but also in their search, development and transformation into practical skills is also increasing (Shaykina, 2014).

Basic theory, events, trends and technology having embraced foreign language teaching in the last decade suggest a technique more like a 'product' of this time, rather than as an educational system. Teachers around the world use different trends in their practice related to the situation, needs and possibilities of available resources and knowledge (Larsen, 2012). Students are also encouraged to be capable to take responsibilities in decision making, applying critical thinking and self-development in learning. Engaging students in interactive forms of work develops their interest and creativity in learning. They realize that in the current innovation development it is necessary to be competitive specialists, thereby to look for ways to self-education purposefully.

Thus, we can say that the priority for the modernization of Russian education is the competence approach, student-centered learning, informatization of education and as a result the transition to a system of continuing education. New educational environment based on the use of information technologies cannot be fully implemented only within the traditional full-time education. Accordingly, one of the ways to solve the current problem is to use the form of blended learning.

\section{Literature Review}

What is blended learning? The term blended learning first appeared around 2000 and was at that time often associated with simply supplementing traditional classroom learning with self-study e-learning activities. Charles Graham describes the historical emergence of blended learning as the convergence between traditional face-to-face learning environments 
and computer-mediated (or distributed) learning environments (Bonk \& Graham 2004; Graham, 2006). More recently, the pedagogic value of providing blended learning opportunities has received significant attention, and the term has evolved to encompass a much richer set of learning approaches and environments (see Adas \& Bakir, 2013; Eydelman, 2013; Gleason, 2013; Krasnova \& Sidorenko, 2013). According to Debra Marsh today blended learning can refer to any combination of different methods of learning, different learning environments, different learning styles (Marsh 2012, p. 6). Elliot Massie considers blended learning as the central theme of his chapter on "The Blended Learning Imperative" and emphasizes that all great learning is blended (Bonk \& Graham 2004, p. 7).

Proceeding from the definitions listed above blended learning is an innovative teaching method, which combines different methods of learning supported by flexible interactive platforms and resources that offer new approaches in improving skills and upgrading competences.

Nowadays Russian education is experiencing the initial stage of formation and development of blended learning, which is also referred to as integrated, combined or hybrid. The concept of blended learning suggests that under current conditions the educational system up-to-date methods of traditional education can be optimally combined with the advantages of remote technologies. Face-to-face courses can be organized more effectively when the significant part of the material is acquired by students on their own using any Internet learning environment or resource. Blended learning system also provides practical approaches to one of the main tasks of modern traditional education is that the development and implementation of student's abilities, skills and competences.

Based on the definition four components of blended learning can be singled out:

- Face-to-face classroom activity facilitated by teacher or instructor, it represents a traditional format of studying.

- Online learning comprises different types of activities, such as searching the information on the Internet, then classifying and analyzing it. This is normally performed by students unassisted.

- Collaborative learning activity - an online cooperative work of students and instructors or teachers organized in Skype or webinars format, forums for discussions on topics of interest.

- Independent study, that is often structurally integrated and guided by skills developed during the classroom experience.

The method of blended learning can enhance the effectiveness of the educational process in a changing paradigm of modern education if the components are applied in a methodically right way and an adequate content is logically put into practice. Both teachers and students have been challenged by new roles which are coherent with the ones described in the literature when new technology is integrated in the class. In general, teachers are guides and collaborators who support students and provide feedback. They challenge learners' thinking and design language learning tasks. Students are autonomous learners who participate actively and are responsible for their learning process (Banados, 2006). The following strengths of blended learning have been identified:

1. Providing an individual and productive learning activity. It develops a personalized constructive thinking and ability to take responsibility for students' own learning. It should be born in mind that in early stages of implementing e-courses or online educational resources some students need guidance as to understand that this flexibility does not mean freedom from classroom routine environment.

2. Increasing student's obligation in learning. It evolves the ability to find solutions and expand information processing skills that are vital to successful independent learners. The strong point is not "obligation" in its direct meaning thereby making students be restricted in cognitive activity promotion, but obligation in learning under conditions of unstrained work due to the use of information technologies.

3. Encouraging collaborative learning. It is provided with collaborative writing, self-assessment and peercorrection, forums for discussions based on different educational platforms or open educational resources. It also helps students indentify their strong and weak points when performing the task in pairs or buddy groups providing each other work with appropriate activities online. Depending on the technology used, blended learning can function as facilitating interaction online, so for example encouraging students to start new discussions relevant to their areas of interests.

Blended learning is considered to be the most innovative approach of the past years especially when it is well organized and implemented into educational process to support deep and meaningful learning. So how can the most effective blend be chosen? The focus is not on the best or right blend that can be taken from various online educational platforms or open educational resources, but on the creation of the learning environment that is up-to-date and flexible and works as a whole (Neumeier, 2005). When considering the creation of learning environment, a simple mixture of information technologies with face-to-face classes should not be confused with blended learning exploitation. Thus, the aim of teachers or tutors using blended learning approaches is to find a rational balance between online support and 
face-to-face interaction. Taking this into consideration, a number of essential factors to achieve an effective blend have been singled out.

\subsection{Support}

Being that blended learning is technologically supported method, so this factor can be divided into two ways: instructional and technical. The instructional way is complied with providing considerable satisfaction for learners. This is accomplished when the teacher encourages students to discuss the issues they find difficult or respond to their peer's questions (online peer-to-peer or group discussion), also gives an appropriate feedback to their activities no matter if they take place in or out of class. Unfortunately technical support also depends on Internet providers, so the outcomes can go wrong in case of doing the blend or e-course in a short period of time. The teacher should predict possible challenges on this issue and be flexible in such vital situations.

\subsection{Cooperation of Blends}

The choice of material is critical. Teachers need to evaluate online resources carefully and use only those materials that are methodologically efficient and appropriate to the educational program (Marsh 2012). It is important for the different types of open blended learning resources to complement each other and satisfy students' needs.

Therefore, the main point for cooperation of blends is to define educational goals (they can be established even for a single unit or lesson) and students' needs and opportunities. In other words the teacher is to identify how best the established goals and needs can be provided with different "ingredients" of the blends to make the learning process coherent and efficient (Marsh 2012).

\subsection{Evaluation}

In blended learning there is more orientation on student self-directed learning that is why teacher's role in evaluating their results must be significant. This factor deals not only with a particular feedback, but structured and detailed final product presented by students. The final work can be performed in a form of writing an essay assessed by peer-correction or presentation introduced in a face-to-face format, or group-work projects for getting points. That is a strong motivation for every student to get the final mark, to be assessed at a high level in our age of competitiveness.

\section{Open Educational Resources}

Learning foreign languages constitutes a significant part of an educational program in Tomsk Polytechnic University. Teachers do much for variability and flexibility of the learning process to make students be able to accumulate much information in condition of limited hours.

\subsection{Moodle}

One of the most effective resources widely used in Tomsk Polytechnic University is a Virtual Learning Environment Moodle. The online course named "The world of work" has been developed and embedded in Moodle environment. The aim of the developed e-course is the formation of foreign communicative competence to provide successful intercultural communication in a professional area. The course is intended to the 2-year students of intermediate level (3 semester). It consists of three modules: "The world of work", "People and workplaces" and "Reversing roles". The knowledge obtained in the course will help students to apply language skills in their professional area as preparing a CV, when being interviewed, also to acquire grammatical structures typical for professional communication.

As a matter of fact, this course has been designed for a definite group of a definite level but the educational curriculum is the same in General English taught for 2-year students in Tomsk Polytechnic University. The only one difference is the specialty. In this case, the developed courses should enable flexible organization of the learning process in order for creators to be competent to update the course for this or that specialty. We consider that the most effective way to innovate the blended learning process is to use open educational resources (OER).

Open educational resources are online materials used to support education that may be freely accessed, downloaded, reused, modified and shared by anyone. The most significant benefit of OER is the variety of materials that can save the time for teachers when preparing for the lesson and looking for a way to implement new ways of learning. 
OER is typically published and distributed through the Internet carrying a copyright license that permits free and unrestricted reuse. Some resources that are freely used for academic purposes are enumerated below.

\subsection{GoConqr}

GoCongr is an online platform for creating and sharing content in multiple formats that students can consume in their own time. The use of the GoCongr tools within the class is intended to work together in groups or individually facilitating discussions and testing overall knowledge. With the emphasis on student content creation and discovery, this resource can be chosen for problem based learning. Students can brainstorm and practice new vocabulary using Mind Maps, Flashcards or Quizzes and share conclusions through Notes. As for the teachers (they are in the role of Admin), so they can create an appropriate content of tasks and keep it private, publish or share it with a private group or embed on a website. For example, Admin can create several groups for students of different specialties and levels and the students are to work only within the created content. The process of logging in is very simple and is performed with the help of google or facebook accounts or by an e-mail.

\subsection{Emaze}

This resource is based on the creation of online presentation software. The presentations made with the help of templates presented on this site are different from widely known Power Point presentations or Prezi Internet program, they have choice transitions, backgrounds and font options that enable content to truly stand out and impress audiences. The user just selects any of professionally designed free presentation templates and creates an amazing visual experience. Also this site features a proprietary state of the art HTML5 presentation maker that will create the slideshows, video presentations and 3D presentations. The interface is rather simple that allows students to create presentations in minutes using ready-made templates. The presentation may be viewed and edited on any computer, laptop, tablet or smartphone that is very comfortable in our technologically advanced world. By the way, Power Point presentations can be imported to Emaze and this process is described in FAQ's chapter. Anyone can be easily registered by entering an e-mail and creating a password.

\subsection{HumBox}

The has been created to publish excellent teaching and learning online resources for free download and sharing. The aims are:

1. to discover, review and revise digital resources from a range of Humanities disciplines and to share them as open content;

2. to provide a trusted and sustainable community repository;

3. to create an expanding national community of peers committed to sharing and reviewing online resources from a range of subject areas in their own disciplinary contexts, which have a global reach;

4. to embed the culture of shared, open educational resources across the Humanities community fostering an increased awareness of and commitment to sharing Humanities resources;

5. to meet the need for a light touch process of peer review and quality enhancement in the delivery of shared learning resources;

6. to provide solutions to practical obstacles inhibiting the sharing or resources across the Humanities;

7. to create a robust model to sustain the further development of HumBox in the future.

The HumBox is a widely used platform for storing, managing and publishing teaching resources on the web. Teachers can share handouts, exercises, podcasts and videos, collaborate with others to peer review and enhance available resources.

\subsection{Scoop.it}

Scoop.it is a content curation technology which is intended to save time finding the content the teacher need. This platform offers:

- to automate content discovery through the big-data semantic technology.

- to select, edit and enrich the most relevant content.

- to publish the content in any social networks, web sites, blogs, newsletters, white-labeled content sites or in a 
private intranet.

So, the panels presented on the site can be embedded to an e-course named as "walls" in order to provide the studied material with extra information.

\section{Conclusion}

Obviously, the role of the teacher who understands and accepts the dynamics of innovative development is changing rapidly. The elaboration of new competences in the framework of blended learning makes a great contribution into the development of students' skills.

The acknowledged advantage of blended learning education is that the participants of the educational process are in constant contact with the teacher as in face-to-face format so in online environment. The students are encouraged to apply for help if they face difficulties by means of e-mails, social networks or discussion forums within OERs.

This study has been sought to investigate how to prepare English language teachers to create a productive blended learning environment for students. Providing blended learning courses with technical and pedagogical support is very important in English language teaching. It has been also defined that the content support is meaningful and it offers an opportunity to integrate innovative and technological advances of various educational online resources. Current research suggests that the best results come from a blended learning method that can be very timesaving and provides convenience and flexibility of learning with the complementarity of best innovative approaches and practical resources.

\section{References}

Adas, D., \& Bakir, A. (2013). Writing difficulties and new solutions: blended learning as an approach to improve writing abilities. International Journal of Humanities and Social Science, 3 (9), 254-266.

Banados, E. (2006). A Blended-learning pedagogical model for teaching and learning EFL successfully through an online interactive multimedia environment. CALICO Journal, 23 (3), 533-550.

Bonk, C. J., \& Graham, C. R. (2004). Handbook of blended learning: Global Perspectives, local designs. San Francisco, CA: Pfeiffer Publishing.

Eydelman, N. (2013). A blended English as a foreign language academic writing course. In: B. Tomlinson \& C. Whittaker (eds.) Blended learning in English. Language teaching: course design and implementation (pp. 43-51). London: British Council.

Gleason, J. (2013). Dilemmas of blended language learning: learner and teacher experiences. CALICO Journal, 30 (3), 323-341.

Graham, C. R. (2006). Blended learning systems: definition, current trends, and future directions. In C.J. Bonk \& C.R. Graham (Eds.) Handbook of blended learning: global perspectives, local designs. San Francisco, CA: Pfeiffer Publishing.

Krasnova, T., \& Sidorenko, T. (2013). Blended Learning in Teaching Foreign Languages. Proceedings of the 6th edition of the international conference "ICT for Language Learning", Florence, Italy.

Larsen, L.J.E. (2012). Teacher and student perspectives on a blended learning intensive English program writing course. Graduate Theses and Dissertations: Iowa State University.

Marsh, D. (2012). Blended Learning. Creating learning opportunities for language learners. New York: Cambridge University Press.

Neumeier, P. (2005). A closer look at blended learning: Parameters for designing a blended learning environment for language teaching and learning. ReCALL, 17(2), 163-178.

Shaykina, O.I. (2014). To develop the competence upgrade for teaching English grammar students of technical university. Bulletin of Chelyabinsk State University. Education and Healthcare, 13(342-4), 106-109. 
